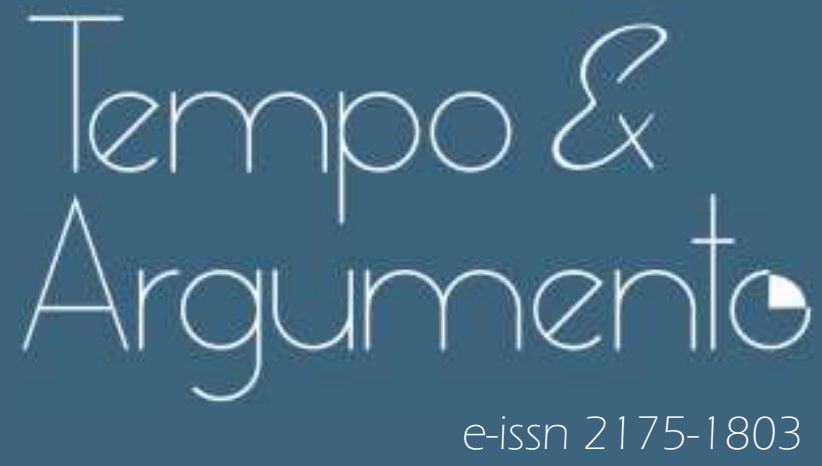

\title{
A História do Tempo Presente, relações de gênero, homossexualidades e a escrita da História
}

\section{Entrevista com}

\& Benito Bisso Schmidt

Doutor em História Social pela Universidade Estadual de Campinas (UNICAMP).

Professor da Universidade Federal do Rio Grande do Sul (UFRGS).

Porto Alegre, RS - BRASIL

lattes.cnpq.br/3067875155143249

bbissos@yahoo.com

(D) orcid.org/0000-0003-3931-2389

Entrevista concedida ̀̀

- Hélio Secretário dos Santos

Doutorando no Programa de Pós-Graduação em História da Universidade do

Estado de Santa Catarina (UDESC).

Florianópolis, SC - BRASIL

lattes.cnpq.br/8957945944717483

heliosecretario@yahoo.com.br

(D) orcid.org/0000-0002-9534-3588

Para citar esta entrevista:

SCHMIDT, Benito Bisso. A História do Tempo Presente, relações de gênero, homossexualidades e a escrita da História. [Entrevista realizada em 30 de setembro de 2020]. Revista Tempo e Argumento, Florianópolis, v. 13, n. 33, e030 1, maio/ago. 2021. Entrevistador: SANTOS, Hélio Secretário dos.

doi dx.doi.org/10.5965/2175180313332021e0301 


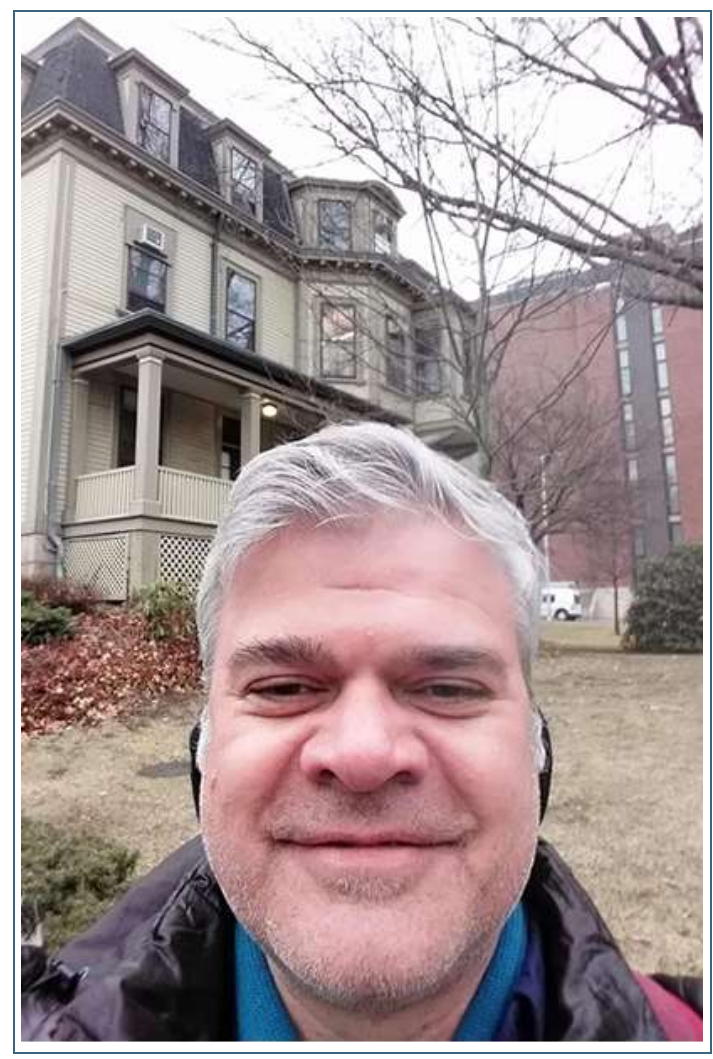

Benito Bisso Schmidt é licenciado (1990) e bacharel (1992) em História pela Universidade Federal do Rio Grande do Sul - UFRGS, mestre em História pela mesma instituição (1996) e doutor em História Social do Trabalho pela Universidade Estadual de Campinas - UNICAMP (2002), com estágio no Centre d'Histoire Sociale du XXe Siècle (Université Paris 1 - PanthéonSorbonne) (2001). Foi professor do Departamento de Biblioteconomia e História da Fundação Universidade do Rio Grande - FURG (1992-1993). Atualmente, é Professor do Departamento (desde 1994) e do Programa de Pós-Graduação (desde 2003) em História da UFRGS. Também integra o corpo docente do Mestrado Profissional em Ensino de História PROFHIST (desde 2014). Foi Maître de Conférences na École des Hautes Études en Sciences Sociales - EHESS, Paris (2005 e 2011).

Foi titular da Cátedra Simón Bolívar do Institut des Hautes Études de l'Amérique Latine - IHEAL (Université Paris 3 - Sorbonne Nouvelle) de janeiro a maio de 2014; professor convidado junto ao Department of Romance and Latin-American Studies da Universidade Hebraica de Jerusalém, em maio de 2014, e ao Mestrado em Ciências Humanas da Universidad de la República (Uruguai), em maio de 2016; e Distinguished Fulbright Visiting Scholar na Emory University (EUA), de agosto a dezembro de 2017. Foi secretário (2002-2004) e presidente (2006-2008) da Seção Rio Grande do Sul da Associação Nacional de História - ANPUH-RS. Integrou a diretoria da ANPUH nacional como segundo tesoureiro (gestão 2009-2011), como presidente (gestão 2011-2013) e como secretário geral (gestão 2019-2021). Foi também vice-presidente da Associação Brasileira de História Oral - ABHO e editor da revista História Oral (2010-2012). Dirigiu o Memorial da Justiça do Trabalho no Rio Grande do Sul vinculado ao Tribunal Regional do Trabalho da 4a Região entre 2008 e 2011. Integra o Grupo de Pesquisa "Teoria e Metodologia da História" e o Laboratório de Ensino de História e Educação (LHISTE), ambos vinculados ao CNPq. Ministra disciplinas na área de Teoria e Metodologia da História e pesquisa sobre temas como: história LGBTQI+ e teoria queer, gênero biográfico, história social da memória, história do trabalho, história das relações de gênero e ditaduras na América Latina. De fevereiro a dezembro de 2018, realizou estágio Sênior no Exterior na Brown University (EUA), com bolsa CAPES.

Conheci Benito no 30 Simpósio Nacional de História realizado na cidade de Recife entre os dias 15 e 19 de julho de 2019, quando participei do Simpósio Temático Clio "sai do armário": homossexualidades e escrita da História. A partir desse encontro, os pesquisadores Benito Schmidt, Rita Colaço e Elias Veras sugeriram a criação da Rede Historiografia LGBTQI+ em maio de 2020 com objetivo de fomentar a produção historiográfica com esse enfoque. Por essa razão, e também pelas abordagens 
historiográficas que compõem a pesquisa de Benito, convidei-o para participar de uma atividade proposta pelo professor Dr. Rogério Rosa Rodrigues, na disciplina História do Tempo Presente: Teoria e historiografia, que compõe a grade curricular do curso de Doutorado em História da Universidade do Estado de Santa Catarina-UDESC. Esta entrevista foi realizada no dia 30 de setembro de 2020.

Agradeço a companheira de curso, Silvia Vitorassi, por ter gravado a entrevista o que demonstra que juntos temos mais força.

Tempo \& Argumento: No artigo, Conhecimento histórico e diálogo social', há uma preocupação com os desafios dos profissionais de História e seus diálogos com as seguintes questões: o ensino de história, a relação dos historiadores com as comissões da verdade e preservação, organização e disponibilização ao público do patrimônio histórico. Benito, quais seriam os desafios políticos e metodológicos postos aos profissionais de História para com as questões de gênero e homossexualidades?

Benito Bisso Schmidt: Esse artigo foi publicado em 2014, ele é uma versão revisada da minha conferência no Simpósio Nacional da ANPUH que aconteceu em Natal (RN). Fui presidente da ANPUH no biênio 2011-2013 e é praxe que o presidente ou presidenta faça o encerramento fazendo um balanço analítico, não só uma prestação de contas, mas tentando inserir diversas questões que tinham se colocado e que me pareceram importantes de serem discutidas. Modestamente, uma espécie de legado para as gestões que viriam depois. Nesse momento, não me preocupava como historiador com a questão da história LGBT. Sou um homem gay cis e, embora essa seja a minha orientação sexual, minha identidade de gênero, não era meu objeto de análise como historiador. como todos nós, eu jamais poderia imaginar os desafios que viriam depois em termos da política, do cenário internacional e nacional. Naquele momento, nós tínhamos questões como a participação de historiadores e das historiadoras na Comissão Nacional da Verdade, questões relacionadas ao ensino de História. O Movimento Escola sem Partido ou essa mentira da ideologia de gênero, embora já estivessem circulando, não tinham assumido essa força política como assumiram depois. O Brasil tem um histórico de violência contra pessoas LGBTQI+, especialmente contra as pessoas trans, porém a gente não pode 
atribuir tudo ao governo Bolsonaro, mas essa não era uma questão central naquele momento; para mim como cidadão, sim, mas não como pesquisador de história. Nosso principal desafio agora, como cidadãos, é lutar pela democracia, não a democracia na concepção formalista de que as instituições estão funcionando, mas uma luta aguerrida envolvendo pactos estratégicos entre os diversos grupos subalternizados da sociedade como mulheres, pretos, pardos, periféricos, pessoas LGBT, enfim estamos numa luta quase pela sobrevivência. Claro que falo de uma posição privilegiada de um intelectual de classe média, branco, cis. É uma questão de lutar pela sobrevivência, por direitos que foram duramente conquistados. Agora mesmo tivemos a equiparação da LGBTfobia ao crime de racismo no Supremo Tribunal Federal, mas sabemos que a lei é um campo de disputa, que a lei em si não basta. Então, o grande desafio de nós historiadoras e historiadores é nos colocarmos com os equipamentos que a nossa disciplina nos dá para pensar o tempo, para pensar a política, para pensar a relação entre a ação dos sujeitos e das sujeitas e os constrangimentos estruturais, usando essas reflexões que são tão caras a nossa disciplina. Que nos coloquemos à frente na luta pela democracia, pelos direitos humanos no sentido mais profundo, não só no formalismo. Nas universidades e nos programas de pós-graduação, de forma bem mais concreta, a luta pela diversidade no espaço das instituições, e aqui me refiro às políticas de ações afirmativas para esses grupos subalternizados, que essas políticas atinjam tanto a graduação como a pós-graduação e o recrutamento de professores. Enquanto nós não tivermos diversidade no corpo docente, estaremos perdendo. Não é só uma política de reparação; a universidade ganha quando seu corpo docente, discente e técnico-administrativo é mais diversificado. No campo específico da história LGBT, é interessante que, nesse contexto tão adverso em termos políticos, as discussões sobre gênero e sexualidade estejam se fortalecendo, o que me parece um alento a nossa capacidade de resiliência e resistência. Os historiadores e historiadoras de história LGBT têm o desafio das fontes, não que elas não existam, mas quem estuda os subalternos e as subalternas vai ter problemas com as fontes; não é uma questão peculiar da história LGBT, mas temos que nos empenhar na produção de fontes, por exemplo, de fontes orais, na preservação de acervos privados. Sabemos que, muitas vezes, as famílias têm vergonha das pessoas LGBT e quando do falecimento de algumas dessas pessoas, 
as famílias não têm a compreensão da importância de materiais escritos guardados, fotografias, flyers de boates. Esse é um desafio das fontes que merece um investimento de nós que nos interessamos, não apenas em produzir, mas também de disponibilizar ao público. Basta vermos que quando o jornal Lampião da Esquina foi digitalizado e disponibilizado, as pesquisas sobre o ele se multiplicaram. Do ponto de vista acadêmico, há o desafio da legitimação historiográfica, ou seja, a história LGBT não dever se voltar apenas para esse campo específico como uma coisa meio do gueto, mas temos que mostrar como as pesquisas sobre experiências, processos e discursos, que têm a ver com a história LGBT, podem dialogar com a História em termos amplos. É possível pensar questões básicas do conhecimento histórico como narrativa, prova, tempo, sujeito, estrutura a partir dos nossos ensaios desse campo específico para consolidar uma historiografia LGBT, fazendo nossas pesquisas interpelarem a História como um todo e isso tem sido feito.

Tempo \& Argumento: "Afinal, se a visibilidade de 'frescos', 'viados' e 'moças meio assim' no ambiente de trabalho poderia implicar, na perspectiva de trabalhadores e dirigentes sindicais, perda de respeitabilidade das lutas da classe operária, sua visibilidade nas pesquisas talvez também retire, aos olhos de muitos investigadores e investigadoras, a respeitabilidade desse campo de estudos". Esse trecho consta no artigo complexificando a interseccionalidade: Perspectivas queer sobre o mundo do trabalho, página 38 de 2019. Benito, até que ponto podemos dizer, ou não, que muitos profissionais da área de História deixam de pesquisar temas LGBT por acharem que suas pesquisas não serão respeitadas pelos seus pares? Seria esse o motivo para uma escassez dessas pesquisas? É possivel fazer uma breve avaliação dos estudos sobre essa temática?

Benito Bisso Schmidt: A minha trajetória inicial como historiador foi na área de história social do trabalho. Fiz Mestrado e Doutorado estudando socialistas no final do século XIX e início do século XX, em Porto Alegre. Depois, eu tive um engajamento muito forte na discussão sobre Justiça do Trabalho no Brasil, era um trabalho com processos trabalhistas. Sou um dos fundadores dos Grupos de Trabalhos de História do Trabalho da ANPUH e quando eu vou estudar os LGBTs são pessoas que trabalham também. A área de história do trabalho é uma área de ponta 
na historiografia brasileira com muitas relações com as questões étnico-raciais, com as discussões de gênero. Me pareceu que as discussões em relação às sexualidades não eram algo muito revisitado, principalmente de sexualidades dissidentes. Claro que nós temos trabalhos importantíssimos sobre a mulher operária, a sexualidade da mulher operária, políticas de controle da natalidade, mas sobre as sexualidades dissidentes me parece que é uma área pouco trabalhada. Quando eu estava fazendo Pós-Doutorado na Brown University, tive contato com uma bibliografia muito vasta sobre trabalho e história LGBT, o que me inspirou para o título do texto "Complexificando a interseccionalidade"2, ou seja, nós podemos sempre complicar a interseccionalidade para além de classe, raça e gênero, aquela tríade básica, mas também levando em conta questões de orientação sexual. Quanto ao meio acadêmico, ele é histórico e profundamente pautado, embora tenha uma autonomia relativa como diz Bourdieu ${ }^{3}$, pelo jeito que a sociedade funciona. Então, se a nossa sociedade é patriarcal, machista, misógina, transfóbica, homofóbica, isso tudo estrutura a universidade. Claro que no sentido específico de funcionamento, provavelmente em outros espaços, gays, lésbicas e bissexuais encontrariam pouco espaço de empregabilidade. O serviço público, de uma maneira geral, é um espaço muito importante para empregabilidade de pessoas com sexualidades dissidentes, por isso temos que defendê-lo. Sabemos que essas regras são tensionadas por uma série de microrregras e microfascismos que atuam no cotidiano. Por exemplo, para determinar quem ocupa os cargos de direção, até que ponto mulheres, negros e negras ocupam cargos de direção? Em relação aos gays, especificamente aqui falando um pouco da minha trajetória, é algo do tipo: que gay você pode ser dentro da universidade? O que é o gay respeitável? Aquele provavelmente branco, de classe média e que siga todos os rituais que a comunidade acadêmica chancela. Além das questões institucionais, e que nós temos que lutar por elas no serviço público, temos a questão das exclusões que vão se dando em diversos níveis. Pensando no trabalho de Ronaldo Vainfas ${ }^{4}$, historiador conhecido que pesquisa o período colonial que estudou

\footnotetext{
SCHMIDT, Benito Bisso. Complexificando a interseccionalidade: Perspectivas queer sobre o mundo do trabalho. Revista Mundos do Trabalho (online), v. 10, p. 31-41, 2019

BOURDIEU, Pierre. O poder simbólico. Tradução de Fernando Tomaz. 13. ed. Rio de Janeiro: Bertrand Brasil, 2010

4 VAINFAS, Ronaldo. Trópico dos pecados: Moral, Sexualidade e Inquisição no Brasil. Rio de Janeiro: Civilização Brasileira, 2010.
} 
sodomitas, me parece que isso não tenha sido um problema pra ele. Eu não calculei pesquisar história LGBT apenas quando estivesse mais fortalecido academicamente, contudo, o fato de eu estar mais posicionado na carreira acadêmica me fortalece pra emprestar a minha respeitabilidade, os meus capitais simbólicos para essa área também. É isso que eu tenho tentado fazer. Agora, isso não impediu que eu fosse incluído em dossiê, ${ }^{5}$, produzido pelo Ministério da Educação apocrifamente, dizendo que o tipo de pesquisa que eu faço, que os professores Elias ${ }^{6}$, Fábio ${ }^{7}$ e Rodrigo Sá Motta ${ }^{8}$ fazem é desperdício de dinheiro público. Havia até nossas fotos nesse dossiê que foi distribuído para parlamentares. Claro, a gente tem uma certa segurança dada pelo serviço público, pelo nosso prestígio na área. Há perseguições e, por isso, temos que pensar nessa luta pela democracia. Não é o governo Bolsonaro que faz tudo, é a sociedade também. Sempre vamos ter coleguinhas, às vezes por homofobia mesmo ou por frustrações por não terem a mesma carreira, que vão se prestar à perseguição. Isso aconteceu nas universidades em 1964 e 1968, quando vários professores foram expurgados porque foram denunciados por colegas como comunistas, mas era muito mais uma rivalidade pessoal. Eu, particularmente, nunca senti um óbice maior pelo que eu faço porque os dominados nos diversos planos da vida social aprendem a se defender.

Tempo \& Argumento: CLOSE - Centro de Referência da História LGBTQI+ DO RS (2019), foi criado com objetivo de incentivar a pesquisa e a divulgação da história LGBT de Porto Alegre ao longo do século XX. focando em personagens, espaços, eventos e processos relacionados às sexualidades desviantes da heteronormatividade.
a) Como foi criado, quem faz parte/coordena?
b) Qual a representatividade de pesquisadores(as) LGBTQI+ na composição do centro?
c) Quais são os temas mais investigados?

\footnotetext{
5 Segundo o então ministro da Educação, Abraham Weintraub (2019), professores universitários ligados à esquerda não produziriam trabalhos relevantes ao conhecimento.

${ }^{6}$ Elias Ferreira Veras autor de Travestis: Carne, tinta e papel (2017).

${ }^{7}$ Fábio Henrique Lopes, autor de Possibilidades de conexão. Michel Foucault, relações de gênero e estudos queer (2017).

8 Autor dos livros "Em guarda contra o perigo vermelho: o anticomunismo no Brasil" (2002) e "As universidades e o regime militar” (2014).
} 
Benito Bisso Schmidt: A criação do CLOSE está inserida nesse momento delicado pelo qual o país passa. Tenho um projeto de pesquisa em que recebo uma bolsa de produtividade do CNPq; nele, trabalho com História e as questões de memória dos LGBTS. O CLOSE foi agraciado com financiamento do edital Universal do CNPq. Certamente, devido à política do Governo de ataques a essa temática, esses projetos serão cortados. É bom ressaltar que consegui muito menos recurso do que pedi para esse projeto que envolve ensino de História, pesquisa e isso que temos chamado de História Pública. Será lançada uma plataforma contemplando essas três abordagens que será a concretização do Projeto CLOSE: "close nas fontes", "close na sala de aula" e "close nas ruas". O projeto tem o desafio de produzir e congregar fontes para construção de uma história LGBTQI+. Temos a colaboração de Rodrigo Weimer, professor colaborador do PPG em História na UFRGS e historiador do Arquivo Público/RS, que está fazendo um levantamento de processos-crimes envolvendo sujeitos e sujeitas dissidentes da heterocisnormatividade. Há muitas entrevistas que são feitas por pesquisadores de iniciação científica, TCC, mestrado e doutorado que podem ser doadas para a plataforma do CLOSE, claro que com as devidas autorizações. A ideia do "close nas ruas", prejudicada por conta da pandemia, era fazer atividades de História Pública, passeios por lugares que são importantes para memória LGBT da cidade. O "close na sala de aula" envolve principalmente duas coisas: oficina de formação de professores e a produção de um livro paradidático sobre a história LGBTQI+ no Rio Grande do Sul. Essa etapa é a que está mais desenvolvida e tem me dado muita satisfação. A equipe do CLOSE envolve pessoas de diversos estados, com formação acadêmica variada, com diversas orientações sexuais, com diversas identidades de gênero. Temos um conselho consultivo com pessoas da Psicologia, do Direito porque, para produção do paradidático, temos que estar amparados principalmente na legislação para evitar falsas acusações do tipo kit gay ou mamadeira de piroca. Temos a contribuição de professoras e professores do Ensino Básico muito experientes com estas questões em sala de aula. É um projeto que me aquece o coração. O nome do grupo teve várias inspirações, desde o close fotográfico, até a Roberta Close, "dar um close" que é uma gíria do meio. O projeto visa incentivar a produção historiográfica. 
Tempo \& Argumento: Nestes tempos perturbadores pelos quais passamos, uma questão que parece relevante é pensar a fronteira entre militância política e a produção de conhecimento. Nos fale sobre as conexões e desafios presentes nessas duas categorias.

Benito Bisso Schmidt: É uma relação muito possível e até desejável. Eu ando com "pouco saco" de ler trabalhos que não expressem um certo tipo de engajamento. As pessoas podem pesquisar o que quiserem, porém há o horror dessas políticas atuais do CNPq que delimitam quais as áreas que serão prioritariamente financiadas. Um problema principalmente para as ciências humanas, as artes e as letras. Essa é uma discussão clássica na historiografia, não é só a questão do lugar de fala que impulsiona o debate, potencializa, mas ela vem desde a constituição da historiografia mesmo: a relação entre engajamento e produção científica. Todos os historiadores tradicionais estavam engajados em um projeto político de constituir as nações, de constituir os Estados Nacionais. Na verdade, a pergunta deveria ser: "quando não houve engajamento?" É uma discussão antiga que partiu do próprio marxismo de que o trabalho mais ideológico é aquele que não mostra as suas motivações ideológicas. Temos que nos colocar em nossos trabalhos para que nossos leitores e leitoras possam avaliar se as nossas prédisposições políticas e ideológicas afetam, e logicamente afetam, mas em que medida afetam os nossos trabalhos. Isso não significa construir um essencialismo histórico, ou uma positivação, sei lá de heróis ou heroínas da história LGBT. Isso significa mostrar o nosso lugar de fala e deixar explícito nosso caminho metodológico, nosso trato com as fontes. Falei anteriormente de rituais acadêmicos, mas talvez o nosso ritual mais bacana seja a avaliação dos nossos pares. São eles que dirão se esse engajamento prejudicou ou ajudou no aprofundamento historiográfico de conhecimento sobre aquela área. São posturas absolutamente compatíveis. Temos que ser conscientes sobre nossos engajamentos e deixá-los bem explícitos.

Tempo \& Argumento: Na sua trajetória de investigar percursos individuais e construir biografias históricas, conforme consta no artigo Quando o historiador espia pelo buraco da fechadura: biografia e ética', por que você considera a ato de biografar como "roubar" a vida dos outros?

9 SCHMIDT, Benito Bisso. Quando o historiador espia pelo buraco da fechadura: biografia e ética. História (São Paulo. Online), v. 33, p. 124-144, 2014. 
Benito Bisso Schmidt: Novamente, nessa linha de contextualizar os textos, esse foi de uma conferência do Simpósio Nacional da ANPUH no Ceará (2009), cujo tema geral foi História e Ética. É curioso que por esses dias está sendo julgado pelo STF um processo sobre direito ao esquecimento que trata de um caso de uma menor de idade que foi violentada e assassinada durante a ditadura. Um certo programa de TV fez uma matéria sobre o caso e a família está pedindo que o mesmo não venha mais a ser exposto publicamente. Há uma questão superimportante das pessoas quererem ver sua privacidade preservada, mas é algo extremamente perigoso para a vida política, para a democracia. Acho que talvez tenha que se preservar as pessoas; uma questão importante é: o nome dessa pessoa é fundamental para o teu argumento? No meu caso, que fiz biografia, os nomes dos biografados sempre foram fundamentais. Antes de me preocupar com história LGBT fiz um trabalho sobre Flavio Koutzii10, político que participou da luta armada contra ditadura. Algumas pessoas que participaram da luta armada com ele pediram para eu não colocar o nome porque isso poderia prejudicá-las até hoje no emprego, por exemplo, e não era fundamental que eu colocasse o nome delas. Aí eu colocava: "um companheiro de Flavio que militou com ele na mesma época disse que...". Se é uma situação que envolva a exposição de uma intimidade que pode causar problemas e que esse nome não é fundamental para argumentação, para o teu problema de pesquisa, não vejo motivo pra colocar. Penso que temos que preservar aquelas pessoas, ainda mais as pessoas que podem sofrer hoje com os preconceitos. Mas acho que os agentes da repressão temos que citar sim; policiais, delegados que eventualmente contribuíram para ocultação de casos ou que emitiram palavras preconceituosas, para mostrarmos que essas pessoas foram cúmplices de um Estado homotransfóbico. Mas aí eu insisto, se isso não for causar problemas. Temos que pensar na nossa proteção como pesquisador. Agora, de pessoas que foram assassinadas, que envolvem questões que ainda hoje podem causar constrangimentos, é melhor usar iniciais, pseudônimos.

10 SCHMIDT, Benito Bisso. Flávio Koutzii: biografia de um militante revolucionário. Porto Alegre: Libretos, 2017. 
Tempo \& Argumento: Pretendo investigar como as categorias gênero, masculinidades e sexualidades ajudam a compreender os assassinatos de cinco pessoas na cidade de Teresina nas décadas de 1970 e 1980. 0 primeiro e o segundo caso, segundo os jornais, tiveram uma motivação passional; os três últimos foram clientes assassinados por supostos garotos de programa. Desses cinco casos, apenas o primeiro teve como vitima uma mulher - empregada doméstica. As três categorias serão capazes de dar conta dessa discussão? Que sugestões você considera indispensáveis para estas propostas de pesquisas?

Benito Bisso Schmidt: Nenhuma categoria vai dar conta da riqueza da experiência humana. Essas pessoas poderiam ser muitas coisas e muitas outras a que nunca teremos acesso. O trabalho de investigação sempre envolve uma escolha e as categorias analíticas nos ajudam a aprofundar determinados aspectos e deixar outros tantos de fora seja porque eles não aparecem nas fontes ou porque não são nosso interesse de pesquisa. Se a categoria de masculinidades, e temos aí longos debates sobre essa ela, é mais útil, se a categoria de sexualidades, de homossexualidades, de sexualidades dissidentes... isso depende do teu interesse de pesquisa, mas de qualquer forma, as categorias que forem escolhidas têm que ser muito bem explicitadas e úteis para responder o problema de pesquisa que tu queres responder. Não adianta fazer uma construção teórica com categorias que não irão ajudar a responder o problema da pesquisa. A velha máxima é colocar a teoria em diálogo com as nossas pesquisas específicas; a questão é: onde determinada categoria pode te ajudar a ler uma fonte, processo, entrevista de uma maneira mais sofisticada? Não há um estoque de categorias ideal, depende da pergunta que tu estás querendo fazer e cada uma delas têm desdobramentos que têm que ser conhecidos e que têm que estar em diálogo com teu objeto específico de pesquisa.

Tempo \& Argumento: Como você analisa a relação entre essa "onda conservadora" que identificamos no Brasil com a Teoria Queer e a produção historiográfica? Reflexões? Retrocessos? Avanços?

Benito Bisso Schmidt: Temos uma visibilidade, um aprimoramento também, independentemente de qualquer avaliação mais qualitativa porque não conheço toda a produção, mas quantitativa mesmo. Olha, aquele nosso simpósio lá em Recife teve vários trabalhos de excelente qualidade não centrados apenas no eixo Rio-São Paulo, muito 
espraiados pelo Brasil inteiro para pensar questões das sexualidades dissidentes. Claro que nós ainda temos muito mais trabalhos sobre homens cis gays do que sobre lésbicas. Sobre homens trans, praticamente não existem trabalhos na historiografia, o que revela uma hierarquia entre os próprios subalternizados. Vimos ali trabalhos sobre cidades pequenas, não apenas concentrados nas metrópoles. Claro que, quando temos que nos defender, a gente se aproxima para sobreviver psicologicamente, academicamente; a gente se aproxima, se fortalece, procura dar visibilidade aos nossos trabalhos. Também não sei se poderia ser diferente caso o Haddad tivesse vencido... seria muito melhor, nosso trabalho também seria melhor. Uma série de políticas públicas que estão sendo atacadas agora são resultado dos governos petistas com todos os seus limites, inclusive na forma de editais específicos reverberando lutas dos movimentos sociais. Não temos que ver nada de positivo na situação atual, pelo contrário, só de negativo e, por isso, temos que resistir e lutar.

\section{Referências}

SCHMIDT, Benito Bisso. Complexificando a interseccionalidade: Perspectivas queer sobre o mundo do trabalho. Revista Mundos do Trabalho (online), v. 10, p. 31-41, 2019.

SCHMIDT, Benito Bisso. O que pode a biografia. 1. ed. São Paulo: Letra e Voz, 2018. v. 1. 242p.

SCHMIDT, Benito Bisso. Os múltiplos desafios da biografia ao/à historiador/a. Diálogos (On-line), v. 21, p. 44, 2017.

SCHMIDT, Benito Bisso. Quando o historiador espia pelo buraco da fechadura: biografia e ética. História (São Paulo. Online), v. 33, p. 124-144, 2014.

SCHMIDT, Benito Bisso. Conhecimento histórico e diálogo social. Revista Brasileira de História (Online), v. 34, p. 325-345, 2014. 